\title{
Study the Rate and Causes of the Screening Test of the Cervix Cancer among Women in Ardabil City
}

\author{
Roya Motavalli ${ }^{1}$, Tavakkol Mousazadeh², Amir Mousazadeh ${ }^{3}$, Ayda Fallah-Asadi $^{4}$
}

${ }^{1}$ Department of Midwifery Ardabil Branch Islamic Azad University, Ardabil, Iran. ${ }^{2}$ Department of Clinical Psychology Ardabil Branch Islamic Azad University, Ardabil, Iran. ${ }^{3}$ Dentistry Student, Ardabil School of Dentistry, Iran. ${ }^{4}$ Midwifery Department, Qazvin University of Medical Science, Qazvin, Iran.

\begin{abstract}
Background and purpose: Cervix cancer is one of the most common cancers in women, particularly indeveloping countries and Asian countries that many science centers around the world consider the pap smear screening test as the best solution for the control of cervical cancer.Several studies have shown that to tend women for doing a pap smear is regularly decreasing, and about one-fifth of women have not had a pap smear. This study was done to investigate rate and causes of the cervix cancer screening test among women Ardabil. Method: In this cross-sectional study, 300 women referred to health centers in Ardabil were selected by multistage sampling. Data were collected through a researcher made questionnaire. For data analysis, SPSS Software version 18 and descriptive and inferential statistics were used. Findings: The rate of cervical cancer screening test in this study was $48 \%$. The role of knowledge as personal factors of pap smear screening test was significant statistically $(p<0.05)$. Among the risk factors for cervical cancer, there was observed significant relationship between uterine diseases history and number of pregnancies and pap smear test $(p<0.05)$. Of family and social factors on women's education and employment, occupation and level of education was no significant relationship with using pap smear test. However, there was a significant relationship family history of cancer and pap smear test $(p<0.05)$. Conclusion: In all, prevention is always prior to treatment. One of the prevention ways is the screening test. Early diagnosis and early treatment of cervical cancer has a key role. So the female population needs planning by intervention programs for health education and regular screening to prevent cancer.
\end{abstract}

Keywords: Screening tests-cervical cancer-pap smear

Asian Pac J Environment and Cancer, 1 (1), 15-17

\section{Introduction}

Cervical cancer is one of the most common cancers in women, especially in developing countries, including Asia and South America [1]. The mortality rate and disability due to cancer in worldwide this year is 235,000 women. In this case, most of the deaths are from Asian countries and Mexico [2]. Each year, nearly 10,000 American women are diagnosed with cervical cancer and More than 3,700 patients die. Many science centers consider doing the regular pap smear as the best solution for controlling and reducing mortality from cervical cancer [3]. Annually, approximately 17.3 percent in every 100,000 women regardless of age and $27 \%$ in women older than 20 years per 100,000 women is reported the invasive cervical carcinoma [4-5]. One of the main reasons women deaths
Submission Date: 06/18/2018 Acceptance Date: 08/21/2018

approximately 500,000 people annually is the cervical cancer [6]. According to the survey, one third of all cancers can be prevented. Over malignancies in women, diagnostic methods are capable the detecting premalignant conditions, may play an important role in preventing, one of these methods is the pap smear. If sampling is done correctly and with the proper tool, the most important test is to detect changes in cervical cells. In Iran, cancer diagnosis and treatment are attempting to determine on clinical symptoms and pap smear, the rate of sensitivity and accuracy of these methods were 45 and 65 percent. [7]. The various studies have shown that to perform this test decrease incidence and mortality of cervical cancer by up to 90 percent effectively [8]. American College of Obstetrics and Gynecology recommends that women who are active sexually (65-18 ages) should do the pap

Corresponding Author:

Dr. Motavalli roya

Department of midwifery Ardabil branch Islamic Azad University, Ardabil, Iran.

Email: mrmotavalli@yahoo.com 
smear once a year, and if they had three times normal pap smear,the test should be repeated every three years [9]. Augurto and etal in 2002 concluded that 60-20 percent mortality from the cervical cancer can be prevented by screening programs [10]. The World Health Organization recommended by 2010, about 97 percent of married women aged over 18 years and women who start their sexual activity before age 18 , must to do pap smear once a year, and $90 \%$ of women must have a pap smear test every three years [11].

According to a study in the U.S. Disease Control Center (CDC), one in five American women have not done pap smear,and 50 percent of these women have reported they are unaware of how to do pap smear, $88 \%$ of people have announced that they have not done it annually due to lack of medical advice [12]. A study by coughlin on nearly 14,000 women in the U.S. in 2000 showed that About 83 percent of women at least once in three years to do pap smear, And $17 \%$ have not had a pap smear even during his lifetime [13]. Given the importance of cervical cancer screening based on the policies of the Ministry of Health and Medical Education, pap smear test at the health center for women in the age group 65-20 years admitted is done for free. pap smear is one of the easiest and least painful and least-cost of medical tests, with regard to the conditions and features, a large number of women do not welcome the cervical screening programs. The aim of this study was to investigate the extent and causes of cervical cancer screening for women in Ardabil.

\section{Materials and Methods}

This cross - sectional study was conducted among women referred to health centers of Ardebil for one month multi-stage sampling in 2012,characteristics of subjects were being married, being of Iranian descent, having the physical and mental health, and having the ability to read and write, the data collection tool was the researcher made questionnaire, the scientific validity of the questionnaire was confirmed by content validity and so reliability of the method obtained for determining the retest interval in two weeks 0.93 and 0.95 . The number of samples used in the study by Cochran sample size was 300 . Information individually through their responses to the questionnaires was collected. After completing the sample and data was taken to the software version 18 , also the descriptive and inferential statistics were used for data analysis.

\section{Results}

Total of subjects were 300 in the study aged 33.5 \pm 8.74 years. All of them were married. $37.7 \%$ of the total sample were employed $(\mathrm{n}=113)$, and $62.3 \%$ was non-employee $(\mathrm{n}=187), 20.3 \%$ of those under diploma $(\mathrm{n}=61), 32.7 \%$ of high school graduates $(\mathrm{n}=98)$ and $47 \%$ higher diploma $(n=141) .46 \%$ of the total sample, her husband occupation ( $\mathrm{n}=138)$ employed, $50 \%$ free job $(n=151)$ and $3.7 \%$ of husbands were unemployed $(n=11)$. $68.7 \%$ of the population over the wife's education were high diploma $(n=206), 29 \%$ of school education $(n=87)$
Table 1. Distribution of Studied Women than Cervical Cancer Screening Tests and Women's Knowledge and Attitudes Toward the Test

\begin{tabular}{lcc}
\hline Percent & Number & Cervicalscreeninghistory \\
\hline $52 \%$ & 156 & No \\
$48 \%$ & 144 & Yes \\
$100 \%$ & 300 & Total \\
$\chi^{2}=2.982$ & Sig $=0.003$ & Result of Test $\chi^{2}$ \\
\hline
\end{tabular}

Table 2. Distribution of Women Based on Pap Smear Screening Test and Uterine Disease

\begin{tabular}{lcc}
\hline Percent & Number & Cervical screening history \\
\hline $79 \%$ & 237 & No \\
$21 \%$ & 63 & Yes \\
$100 \%$ & 300 & Total \\
$\chi^{2}=4.581$ & Sig $=0.000$ & Result of Test $\chi^{2}$ \\
\hline
\end{tabular}

Table 3. Distribution of Women Based on Number of Pregnancies and Cervical Cancer Screening Tests

\begin{tabular}{lcc}
\hline Percent & Number & Number of pregnancies \\
\hline $7.13 \%$ & 41 & Notpregnant. \\
$45 \%$ & 135 & Less thantwice \\
$3.41 \%$ & 124 & Morethan twice \\
$100 \%$ & 300 & The total \\
$\chi^{2}=0.258$ & Sig $=0.000$ & Result of Test $\chi^{2}$ \\
\hline
\end{tabular}

and $2.3 \%$ illiterate $(n=7)$, respectively.

According to Table 1, the results of this study showed that the rate of cervical cancer screening tests among women was 48 percent. The role of knowledge as factors of pap smear screening test was statistically significant (Table 1) $(\mathrm{P}<0.05)$.

The statistical results in Table 2 and 3 indicate that, at a significance level of 0.05 between diseases of the uterus, there is a significant relationship between number of pregnancies and pap smear. (Table 2 and 3$)(p<0.05)$

In the study, of the social and family factors on women's education and employment, occupation and level of education was no significant relationship with pap smears. However, between ethnic history of cancer and pap smear showed a significant relationship (Table 4) $(\mathrm{p}<0.05)$.

\section{Discussion}

Our findings showed that the mean age of the sample

Table 4. Distribution of Women According to Ethnic history of Cancer and Pap Smear

\begin{tabular}{lcc}
\hline Percent & Number & Ethnic history of cancer \\
\hline $86 \%$ & 258 & No \\
$14 \%$ & 42 & Yes \\
$100 \%$ & 300 & Total \\
$\chi^{2}=0.175$ & Sig $=0.01$ & Result of Test $\chi^{2}$ \\
\hline
\end{tabular}


is 33.5 with standard deviation of 8.74 years, in this age group, 48 percent had a history of cervical screening. In a survey by Mustafa Zadeh etal (2008) was done, the mean age of the 33.68 with standard deviation of 8.9 years was shown [14]. The results of a study entitled. The Causes not to do pap smear showed that 55.1 percent of women who were regularly tested were 36 years [12]. The results of the present study are almost consistent.

The role of knowledge as factors of pap smear screening test was statistically significant. In a study by Khojasteh and colleagues in Zahedan in 2004 as a survey of knowledge, attitude and practice of women in Zahedan about pap smears and cervical cancer was performed,it was found that the relationship between knowledge and attitudes and pap smear significant that is consistent with our results [15].

In a study conducted in Yazd by Baghianiwas determined that $61 \%$ of 300 Yazdwomen with pap smear test are familiar, [7]. However, in a survey conducted by kimk and colleagues, knowledge of American women - Korean called Pap smear, 74\% have been reported [16].The research was done by Mustafa Zadeh and colleagues, pap smear isof the main causes of lack of knowledge (36.1 percent) reported [14]. Taylor etal in their study showed that the lack of information on pap smear is important cause of unwillingness to perform regular and periodic pap smears among women [3].

Of the risk factors for cervical cancer and uterine disease were observed the significant relationship between the number of pregnancies and pap smear. In the study also BaghianiMoghadam knowledge level the women who had 3-2 pregnancies, there were pap smear more than screening test. And other results of his research, the most important reasons for having a pap smear are history of uterine disease (31.8 percent) [7].

Of family and social factors on women's education and employment, occupation and level of education was no significant relationship with pap smear, which is consistent with the results of BaghianiMoghadam in Yazd.

Also In our study was similar to results of Taken etal [17]. In the study of ethnic history of cancer and pap smear was a significant relationship, is consistent with the research of Khojasteh in Zahedan. Several studies inside and outside the country, most cause for not doing of regular pap smear test in women is unaware [14-3]. It seems logical that if ethnic history of cervical cancer to raise awareness as an alarm for ethnic.

In conclusion, always and at all times, prevention is prior to treatment.The screening is one of prevention ways, in the early diagnosis and early treatment of cervical cancer has a key role. Whatever the level of awareness of the target group is high, and their positive attitude in this regard is reinforced, certainly better performance will had in this area. Therefore, the level of their knowledge about the test must to improve by the applied method further. Medical advice for the testing is effective, so if physicians systematically recommend performing this test to clients, much better results will be achieved. Also if describe how to test and absence of side effects for women, and to perform pap smear is routinely In the clinic, participate actively in the screening will increase.

\section{Conflicts of interest}

The authors declare that they have no competing interests

\section{References}

1. Myrian, Patrick. Attitude toward cervical cancer screening: A study of beliefs among women in Mexico journal of health promotion. 2006.4 (2):13-24.

2. Lazcano, P.E moss. Deruiz. Cervical cancer screening in developing countries, Why is it ineffective the case of Mexico, Archives of medical research. 2001; 30:240-250

3. Taylor, etal, Aperiodic abstinence from pap smear study in women. Actaobs journal.2006; 9: 134-140

4. Berekjs.novak gynecology, Ghazijahani B,translator. Tehran: Golban pub. 2004. [In Persian].

5. Society of family planning of Islamic republic of Iran,Education of fertility health. Tehran: Andishmand pub: 2001. P: 6-49. [In Persian]

6. Danfors, david-games scat.midw:fery and women diseases. Translation of Ali yazdaninejad. Tehran. 2008. Page: 1001-1002.

7. Bagianimogadammh, assessment women's knowledge and attitude (15-49ages) Yazdcity about pap smear screening testing in 2001. Journal of Mazandaran university of medical sciences 2005.13 (40):79-85.[Persian].

8. PearsonD.Green Gynecology, Boston:little brown company. 1990.

9. Raff Io AE.Control studies of screening should carry A Health warning,International journal of Epidemiology .2003. 32 (4):577-578.

10. Augurto I Bishopa, etal. Perceived barriers and benefits cervical cancer screening in latin America, Preventive medicine. 2004. 39:91-98.

11. Hoffman m, etal. Limited pap smear screening associated with reduced risk of cervical cancer in South Africa. Inter J of epidemiology. 2003.32 (4):575-577.

12. Smith j.nearly one in five women go without pap smear test. Health pay, 2005 may; 11: 25-28.

13. Coughlins,s. implementation breast and cervical prevention programs the trauma Indians of southern Louisiana cultural and ethical consideration health care poor under saved. 2000:9 (1):30-40.

14. Mostafazadeh, F.mashoofi,M.hagiagamohammadi P.Investigation of the don't doing pap smear test reason from the women's point of view who are referring to remedy centers of Ardabil, Scientific magazine of nursing and midwifery of university of Ardabil, 2008. (10). P: 10-17.

15. Khojasteh f.assessment women's knowledge and attitude about pap smear and cervix cancer in zahedan city, Journal of AhvazUniversity of medical sciences. 2004. (41) p: 16-24.

16. Kimk, yues, chenEH,kim j, kaufman m, purkiss j. university of Illinois at Chicago, usa, Cancer nurse. 1999 agu, 22 (4): 297-302.

17. Tachenm, etal (2007) uptake of cervical cancer screening in the Netherlands is mainly influenced by women's beliefs about the screening and by the inviting organization, The European journal of public health. 17 (2) 178-185.

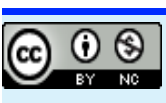

This work is licensed under a Creative Commons AttributionNon Commercial 4.0 International License. 